(2) Open Access Full Text Article

\title{
Improving near vision in presbyopic eyes by selective treatment of high-order aberrations
}

This article was published in the following Dove Press journal:

Clinical Ophthalmology

14 October 201।

Number of times this article has been viewed

Mounir A Khalifa ${ }^{1,2}$

Waleed A Allam ${ }^{1,2}$

Ahmed M Khalifa ${ }^{2}$

'Tanta University Eye Hospital, Tanta, Egypt; ${ }^{2}$ Horus Vision Correction Center, Alexandria, Egypt
Correspondence: Mounir Khalifa 559 Al Horeya Avenue, Gleem,

Alexandria, Egypt

$\mathrm{Tel}+20122154996$

Fax +20 35448744

Email mounir.khalifa 100@gmail.com
Purpose: Evaluation of improving near vision in presbyopic patients with low to moderate myopia with selective treatment of high-order aberrations (HOAs) using the ORK-CAM software aberrometer and a SCHWIND ESIRIS excimer laser. In this study, all HOAs except vertical coma were treated and the effect on near visual function was evaluated.

Setting: Horus Vision Correction Center, Alexandria, Egypt.

Methods: Twenty-six presbyopic patients (52 eyes) with low to moderate myopia were divided into two groups, A and B. The ORK-CAM software aberrometer was used in both groups to measure HOAs and design wavefront-guided treatment. All included eyes had total coma $>0.2 \mu \mathrm{m}$. The Moria M2 mechanical microkeratome was used for flap making in both groups. Wavefront-guided laser-assisted in situ keratomileusis using ESIRIS laser was done for all eyes. In Group A (30 eyes) all HOAs were treated. In Group B (22 eyes) vertical coma was left untreated. Postoperative uncorrected distance visual acuity (UCVA), best corrected distance visual acuity (BCVA), uncorrected near acuity (UCNA), distance corrected near acuity (DCNA), best corrected near acuity with addition for near vision (BCNA), manifest refractive spherical equivalent (MRSE), HOAs, and contrast sensitivity for both groups were done preoperatively and at 3 months postoperatively.

Results: Mean age was 47.46 and 45.2 years for groups A and B, respectively. Mean preoperative MRSE was -2.37 and $-2.87 \mathrm{D}$ and mean preoperative total HOAs was 0.35 and $0.38 \mu \mathrm{m}$ in groups A and B, respectively. There was no significant difference between groups regarding age, sex, preoperative MRSE, and preoperative total HOAs. After 3 months, there was no significant difference between groups in terms of UCVA, BCVA, MRSE, and contrast sensitivity. Analysis of postoperative HOAs showed significant difference in vertical coma between the two groups $(P<0.001)$. DCNA was significantly better in Group B $(P<0.01)$.

Conclusion: Treating low to moderate myopia with wavefront-guided ablation including selective treatment of HOAs might be very useful for improving visual functions. Treating all HOAs but the vertical coma improved uncorrected near acuity in presbyopic patients.

Keywords: presbyopia, vertical coma, wavefront

\section{Introduction}

Presbyopia is an age-related gradual, progressive loss of accommodation with recession of the near point of distinct vision over time. The eye is no longer able to either exert or maintain the accommodation required for clear near vision, necessitating the use of spectacles to enable the patient to see near distance. Intermediate vision, as well, might get affected with time.

Surgical techniques for presbyopia correction are diverse. However, they can be classified into two main approaches based on the mechanism of near vision restoration. 
The first approach aims at restoration of the eye's true accommodative ability, such as anterior ciliary sclerotomy, ${ }^{1}$ scleral expansion, ${ }^{2}$ and accommodative intraocular lenses (IOLs). ${ }^{3}$ The second approach includes restoration of helpful near vision without true gains in the eye's accommodation by means of increasing the depth of focus, that is, pseudoaccommodation. Pseudoaccommodation can be achieved through either corneal techniques or intraocular surgery such as multifocal IOLs. ${ }^{4,5}$ Monovision $^{6}$ is another option that can be achieved via conductive keratoplasty, ${ }^{7}$ excimer laser, or monofocal IOLs.

In 2007, the authors performed an eventless wavefrontguided laser-assisted in situ keratomileusis on a 45-year-old male for moderate myopia. Postoperatively, he was able to see 20/15 unaided. Follow-up wavefront examinations revealed the accidental induction of a huge amount of vertical coma corresponding to an area of minimal ablation decentration on topography. Interestingly, this patient's distance corrected near acuity (DCNA) improved from $20 / 70$ preoperatively to 20/20 after the procedure.

Based on this observation and the fact that not all aberrations are harmful, ${ }^{8}$ this prospective study evaluated the possibility of improving near vision in presbyopic patients with low to moderate myopia through selective treatment of high-order aberrations (HOAs).

\section{Patients and methods}

This prospective consecutive comparative randomized double-masked study was carried out at Horus Vision Correction Center in Alexandria, Egypt, from January to July 2009. Written informed consent was obtained from the patients before their participation in the study.

\section{Patient selection}

Fifty-two eyes of 26 patients, all aged $>40$ years, with symptoms of presbyopia were included in this study. Exclusion criteria were: $<40$ years old, any abnormal or suspicious patterns on corneal topography, central pachymetric measurements $<500 \mu \mathrm{m}$, and history of chronic eye diseases. Patients with lens opacities were also excluded from the study.

Included patients all had low to moderate myopia with best corrected distance visual acuity (BCVA) of 20/20 for distance. All patients had total coma aberration of $>0.2 \mu \mathrm{m}$ at $6.0 \mathrm{~mm}$ pupil diameter. They were randomly divided into two groups, A and B.

In Group A, all HOAs were treated along with the sphere and cylinder. This group included 30 eyes of 15 patients ( 9 females and 6 males), with a mean age of 47.46 years (range 43-51 years). Mean manifest refraction spherical equivalent (MRSE) was $-2.37 \mathrm{D}$ (range -1.75 to $-4.0 \mathrm{D}$ ) and mean total root mean square (RMS) value was $0.35 \mu \mathrm{m}$ (range 0.26-0.53 $\mu \mathrm{m}$ ).

In Group B, vertical coma aberrations were selectively left untreated, while all other HOAs, along with the sphere and cylinder, were treated. This group included 22 eyes of 11 patients ( 8 females and 3 males) with a mean age of 45.2 years (range 42-50 years). Mean MRSE was $-2.87 \mathrm{D}$ (range -2.0 to $-4.5 \mathrm{D}$ ) and mean total RMS value was $0.38 \mu \mathrm{m}$ (range $0.28-0.56 \mu \mathrm{m}$ ). Table 1 shows the preoperative data of the two groups in terms of age, sex, MRSE, and root mean square RMS.

\section{Preoperative evaluation}

All patients were tested for uncorrected distance visual acuity (UCVA), manifest and cycloplejic refractions, and BCVA. Near vision capabilities were also determined at a distance of $40 \mathrm{~cm}$ by testing uncorrected near acuity (UCNA), best corrected near acuity with addition for near vision (BCNA), and DCNA.

All patients were subjected to corneal mapping using the Humphrey ${ }^{\circledR}$ Atlas $^{\text {TM }} 993$ (Carl Zeiss Meditech, Inc, Dublin, CA) Placido-disk corneal topographer, corneal pachymetry, pupil diameter measurement, contrast sensitivity testing using the CSV-1000E (VectorVision, Inc, Greenville, OH) chart, and a detailed slit-lamp examination using the Haag-Streit BM 900 slit-lamp (Haag-Streit International, Bern, Switzerland). ORK-CAM (SCHWIND eye-tech-solutions, Kleinostheim, Germany) software was used for all patients to measure HOAs and design ocular wavefront-guided treatment.

All HOAs were treated in Group A along with the sphere and cylinder, while vertical coma aberrations were left untreated in Group B.

\section{Surgical technique}

All patients had laser-assisted in situ keratomileusis done using the Moria M2 (Moria, Antony, France) mechanical microkeratome for flap creation. A flap diameter of $9.5 \mathrm{~mm}$

Table I Preoperative data showing no significant difference between both groups in terms of age, sex, manifest refractive spherical equivalent (MRSE), and root mean square (RMS)

\begin{tabular}{lll}
\hline Group & A & B \\
\hline No of eyes & 30 & 22 \\
Age (years) & 47.46 (range 43-5I) & 45.2 (range 42-50) \\
Sex & 9 females, 6 males & 8 females, 3 males \\
MRSE & $-2.37 \mathrm{D}$ & $2.87 \mathrm{D}$ \\
& $($ range -1.75 to -4.0$)$ & $-2.87 \mathrm{D}($ range -2.0 to -4.5$)$ \\
RMS & $0.35 \mu \mathrm{m}($ range $0.26-0.53)$ & $0.38 \mu \mathrm{m}($ range $0.28-0.56)$ \\
\hline
\end{tabular}


and thickness of $130 \mu \mathrm{m}$ were intended. Wavefront-guided treatment was performed in both groups using the SCHWIND ESIRIS (SCHWIND eye-tech-solutions) excimer laser platform. Figure 1 shows a wavefront map in a patient preand postoperatively.

\section{Follow-up and data analysis}

Double-masked postoperative follow-up visits were scheduled at 1 day, 1 week, 1 month, and 3 months. The evaluation included measurement of distance UCVA and BCVA, manifest refraction, near UCVA, BCVA, and DCNA.
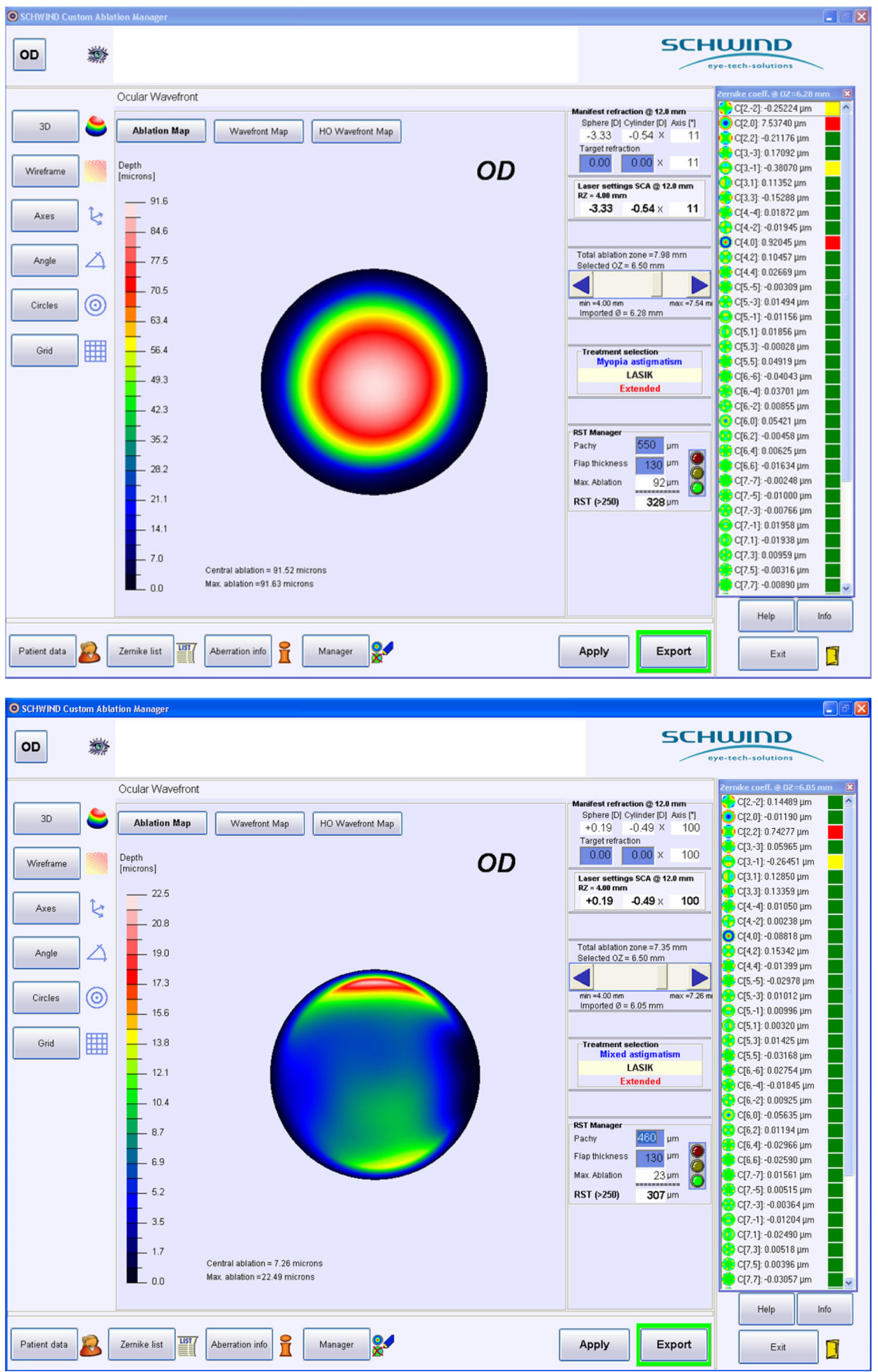

Figure I Wavefront map of a patient in Group B before (A) and after (B) treatment, showing an almost stable amount of vertical coma. 
Corneal topography, contrast sensitivity, and aberrometry were done at 1 and 3 months.

Statistical analysis was performed using the Microsoft Excel 2003 (Microsoft Corp, Redmond, WA) Data Analysis Tool Pak. Paired Student's $t$-test was applied to compare data means.

\section{Results}

\section{Safety}

Safety index of the procedure (ratio of postoperative BCVA to preoperative BCVA) at 3 months was 1.0 and 1.1 for groups $\mathrm{A}$ and $\mathrm{B}$, respectively, with no significant change in the postoperative BCVA compared with preoperative levels. Similarly, the difference in postoperative BCVA at 3 months between both groups was statistically insignificant (Figure 2).

\section{Efficacy}

UCVA significantly improved at 1 and 3 months postoperatively in both groups (Figure 3). All cases in both groups achieved a UCVA of 20/30 or better.

\section{Predictability}

In Groups A and B, 80\% and 70\%, respectively, of cases were within $\pm 0.5 \mathrm{D}$ of emmetropia at 3 months. All cases in both groups were within 1.0 D of emmetropia. (Figure 4.)

\section{Near visual acuity}

BCNA showed no statistically significant differences at 3 months after the procedure in both groups compared with preoperative levels. Similarly, the difference between both groups in postoperative BCNA at 3 months was statistically insignificant (Figure 5). UCNA in Group B was significantly better than in Group A patients $(P<0.001)$ (Figure 6).

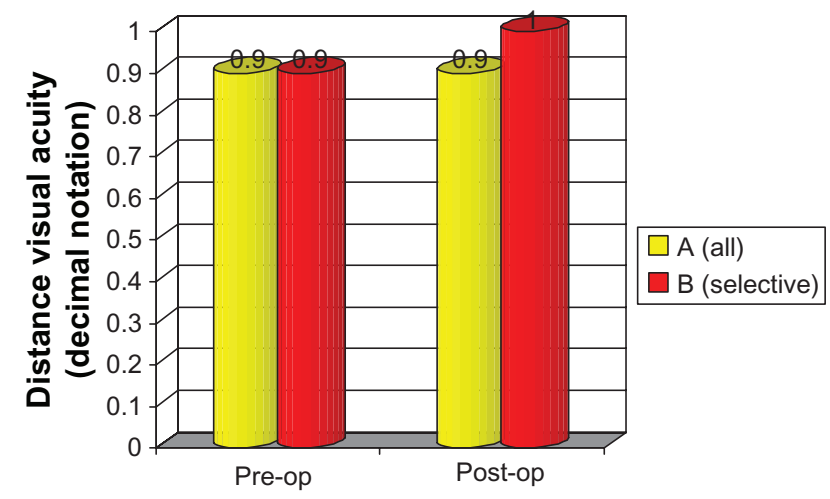

Figure 2 Safety: preoperative (pre-op) versus postoperative (post-op) best corrected visual acuity.

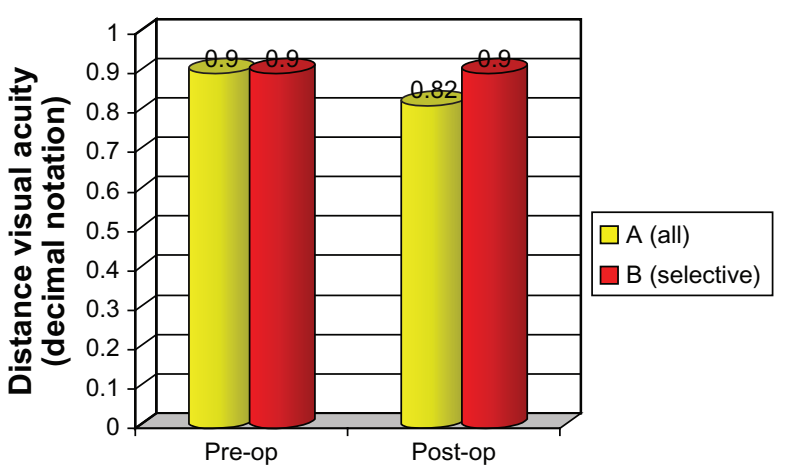

Figure 3 Efficacy: postoperative (post-op) uncorrected distance visual acuity versus preoperative (pre-op) best corrected visual acuity.

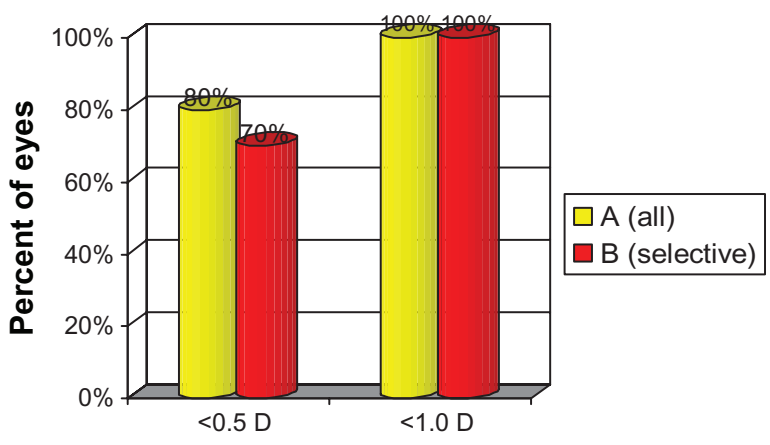

Figure 4 Predictability; the percent of eyes within $\pm 0.5 \mathrm{D}$ and $\pm 1.0 \mathrm{D}$ of emmetropia at 3 months.

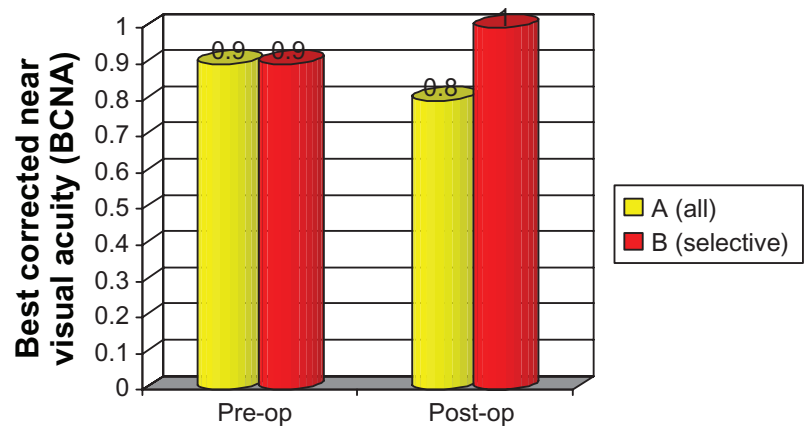

Figure 5 Preoperative (pre-op) and postoperative (post-op) best corrected near acuity with addition for near vision of both groups with the suitable addition showing no significant difference between both groups either pre- or postoperatively.

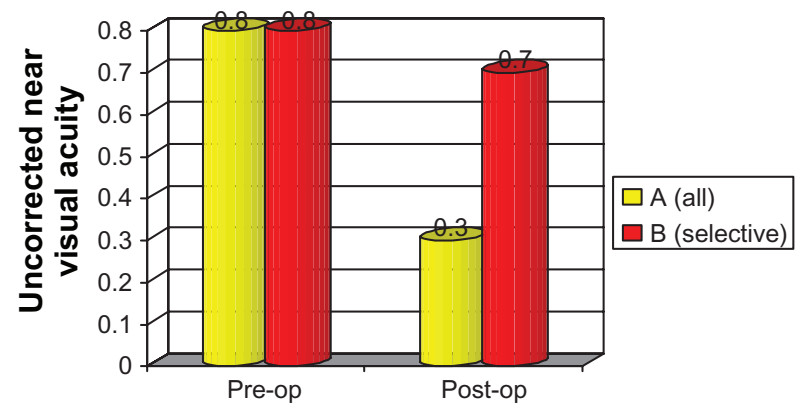

Figure 6 Preoperative (pre-op) and postoperative (post-op) uncorrected near acuity showing no preoperative significant difference between both groups and significant difference postoperatively. 


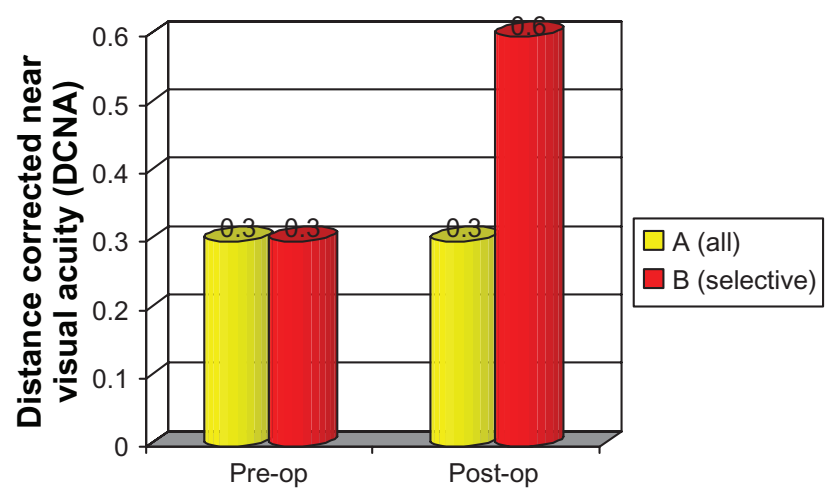

Figure 7 Preoperative (pre-op) and postoperative (post-op) distance corrected near acuity showing no preoperative significant difference between both groups and significant difference postoperatively.

In Group B patients at 3 months after the procedure, DCNA was significantly improved compared with preoperative levels, while negligible difference was recorded in Group A. Postoperative DCNA was significantly better in Group B compared with Group A patients. (Figure 7.)

\section{HOAs and contrast sensitivity}

Three months after the operations, vertical coma was significantly higher in Group B compared with Group A $(P<0.003)$. Other aberrations did not show statistically significant differences between the two groups in the postoperative period (Figure 8).

With regard to the comparison of different HOAs pre- and postoperatively, there was no significant difference, in each group, between pre- and postoperative values except in the vertical coma of Group B, which showed significant increase at 3 months postoperatively $(P<0.05)$. Contrast sensitivity significantly improved in both groups after the procedure (Figure 9). No significant intergroup contrast sensitivity differences were detected in the postoperative period.

\section{Discussion}

Presbyopia correction is one of the most challenging situations in refractive surgery and ophthalmology. The challenges come from the fact that full understanding of accommodation and pathophysiology of presbyopia has not yet been reached. At the same time, presbyopia is the only refractive error that continues to progress with time.

The effect of wavefront aberrations on the quality of vision is quite obvious and several studies have attributed specific visual symptoms to specific types of HOAs. Chalita et $\mathrm{al}^{8}$ showed positive correlation of double vision with total coma and with horizontal coma for the $5 \mathrm{~mm}$ and $7 \mathrm{~mm}$ pupil sizes, negative correlation between starburst and total coma for the $7 \mathrm{~mm}$ pupil size, positive correlation of double vision with horizontal coma, and glare and starburst with spherical aberration and with total aberrations. Melamud et $\mathrm{al}^{9}$ showed that horizontal and vertical coma might be responsible for horizontal and vertical diplopia in symptomatic patients.

Just like all other aberrations, average normal values of coma aberrations vary depending on the pupil size but generally should be approximately $0.35 \mu \mathrm{m}$ for a $7.0 \mathrm{~mm}^{10}$ and $0.28 \mu \mathrm{m}$ for $6.0 \mathrm{~mm}$ pupil diameter. ${ }^{11}$

The authors are unaware of any studies that have correlated vertical coma with near vision abilities. It is assumed that vertical coma at certain magnitudes could improve near

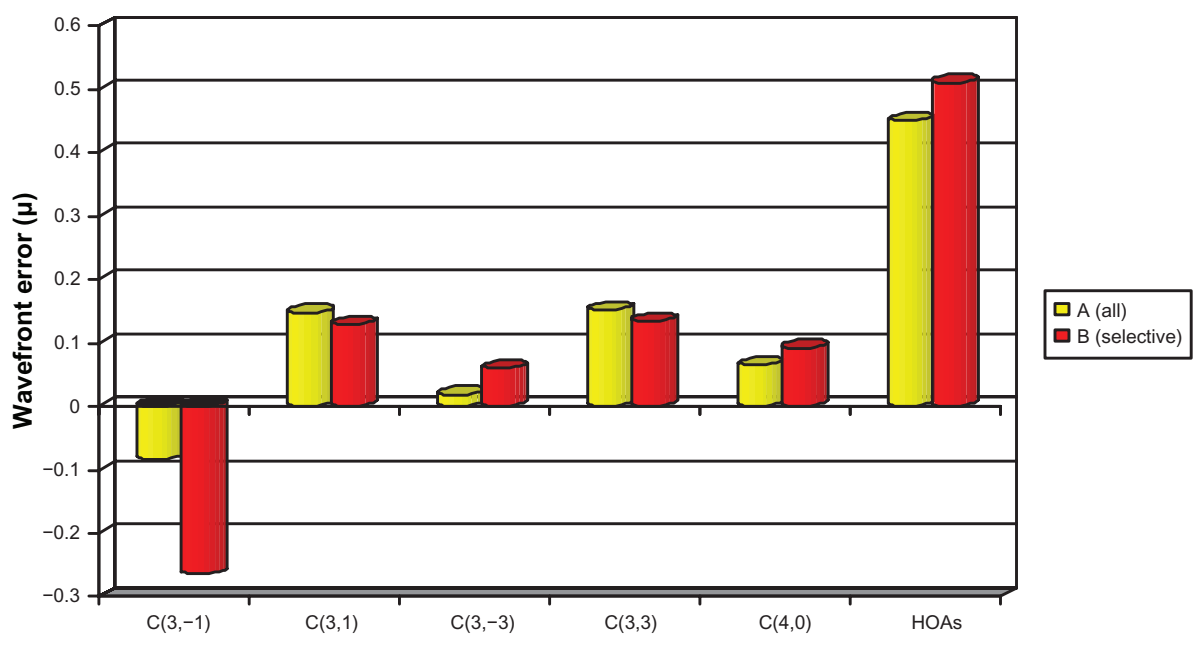

Figure 8 Postoperative high-order aberrations (HOAs) showing no significant difference between both groups except in vertical coma, which was significantly higher in Group B than Group A. 


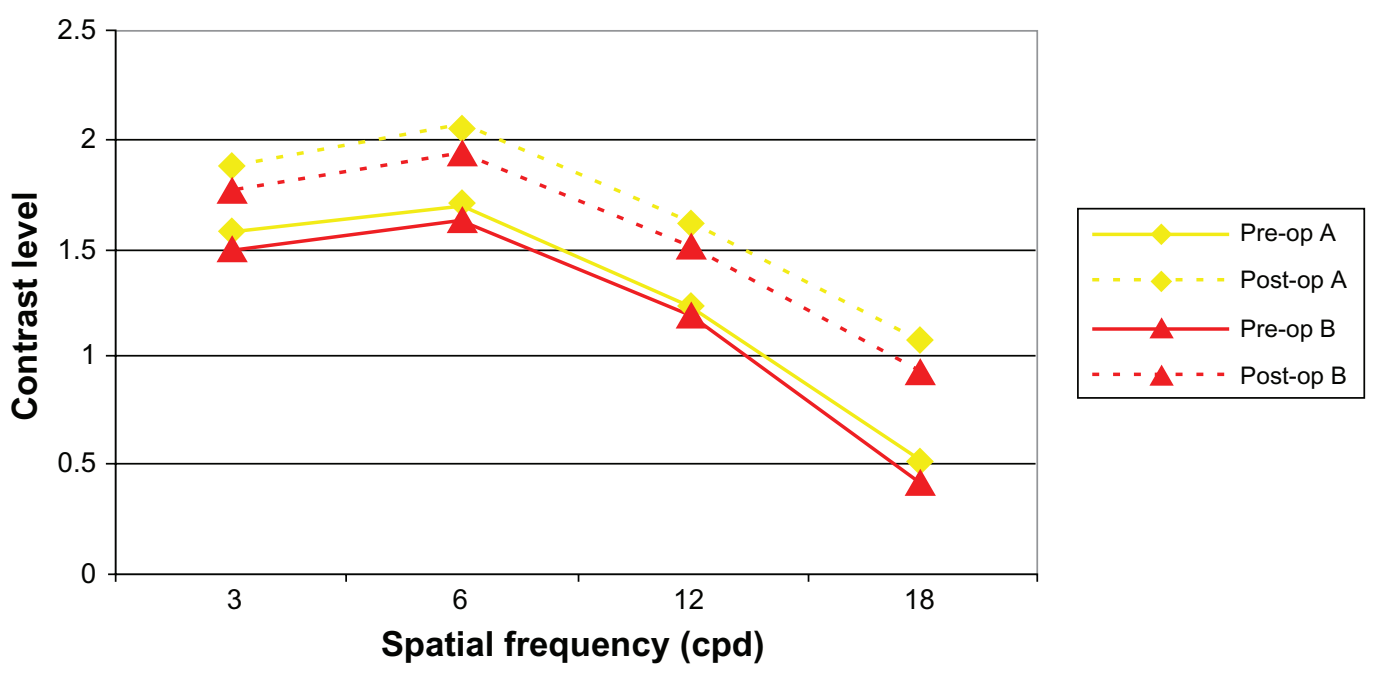

Figure 9 Contrast sensitivity shows no significant difference between groups A and B either preoperatively (pre-op) or postoperatively (post-op).

vision potentials of the eye through increasing the depth of focus. However, to be established, this assumption needs a larger number of cases with longer follow-up periods.

\section{Disclosure}

The authors have no conflicts of interest to declare in relation to this paper.

\section{References}

1. Hamilton DR, Davidorf JM, Maloney RK. Anterior ciliary sclerotomy for treatment of presbyopia: a prospective controlled study. Ophthalmology. 2002;109:1976-1977.

2. Malecaze FJ, Gazagne CS, Tarroux MC, Gorrand JM. Scleral expansion bands for presbyopia. Ophthalmology. 2001;108:2165-2171.

3. Macsai MS, Padnick-Silver L, Fontes BM. Visual outcomes after accommodating intraocular lens implantation. $J$ Cataract Refract Surg. 2006;32:628-633.

4. Montés-Micó R, España E, Bueno I, Charman WN, Menezo JL. Visual performance with multifocal intraocular lenses: mesopic contrast sensitivity under distance and near conditions. Ophthalmology. 2004;111:85-96.
5. Alió JL, Tavolato M, De la Hoz F, Claramonte P, Rodríguez-Prats JL, Galal A. Near vision restoration with refractive lens exchange and pseudoaccommodating and multifocal refractive and diffractive intraocular lenses: comparative clinical study. J Cataract Refract Surg. 2004;30:2494-2503.

6. Jain S, Arora I, Azar DT. Success of monovision in presbyopes: review of the literature and potential applications to refractive surgery. Surv Ophthalmol. 1996;40:491-499.

7. McDonald MB, Hersh PS, Manche EE, Maloney RK, Davidorf J, Sabry M; Conductive Keratoplasty United States Investigators Group. Conductive keratoplasty for the correction of low to moderate hyperopia: US clinical trial 1-year results on 355 eyes. Ophthalmology. 2002;109:1978-1989; discussion; 1989-1990.

8. Chalita MR, Xu M, Krueger RR. Correlation of aberrations with visual symptoms using wavefront analysis in eyes after laser in situ keratomileusis. J Refract Surg. 2003;19:S682-S686.

9. Melamud A, Chalita MR, Krueger RR, Lee MS. Comatic aberration as a cause of monocular diplopia. $J$ Cataract Refract Surg. 2006;32: 529-532.

10. Chalita MR, Finkenthal J, Xu M, Krueger RR. LADARWave wavefront measurement in normal eyes. J Refract Surg. 2004;20:132-138.

11. Schwiegerling J. Scaling Zernike expansion coefficients to different pupil sizes. J Opt Soc A Opt Image Sci Vis. 2002;19:1937-1945.
Clinical Ophthalmology

\section{Publish your work in this journal}

Clinical Ophthalmology is an international, peer-reviewed journal covering all subspecialties within ophthalmology. Key topics include: Optometry; Visual science; Pharmacology and drug therapy in eye diseases; Basic Sciences; Primary and Secondary eye care; Patient Safety and Quality of Care Improvements. This journal is indexed on Submit your manuscript here: http://www.dovepress.com/clinical-ophthalmology-journal

\section{Dovepress}

PubMed Central and CAS, and is the official journal of The Society of Clinical Ophthalmology (SCO). The manuscript management system is completely online and includes a very quick and fair peer-review system, which is all easy to use. Visit http://www.dovepress.com/ testimonials.php to read real quotes from published authors. 